\title{
Profylactische gastropexie bij de hond: een overzicht van de chirurgische technieken
}

\author{
S. David, B. Van Goethem, A. Rubio-Guzman, H. de Rooster \\ Vakgroep Geneeskunde en Klinische Biologie van de Kleine Huisdieren \\ Faculteit Diergeneeskunde, Ugent, Salisburylaan 133, B-9820, Merelbeke \\ bart.vangoethem@ugent.be
}

\begin{abstract}
SAMENVATTING
Profylactische gastropexie wordt aangeraden bij honden die gepredisponeerd zijn om maagdilatatie en torsie (MDT) te ontwikkelen. Bij de traditionele celiotomietechnieken resulteren de circumcostale en de belt-loop gastropexie in sterke adhesies met een minimale kans op MDT. Deze technieken worden echter geassocieerd met ernstige complicaties, zoals iatrogene pneumothorax, ribfracturen of peritonitis. De incisionele gastropexie leidt tot een minder sterke verbinding, maar resulteert toch in een drastische verlaging van het voorkomen van MDT. Vermits met deze techniek bovendien weinig complicaties worden gezien, geldt ze als de huidige gouden standaard. Morbiditeit is een belangrijk aspect voor een preventieve ingreep. Deze morbiditeit kan worden verminderd met minimaal invasieve operatietechnieken. De grote voordelen van laparoscopische gastropexie inzake weefseltrauma en het welzijn van de patiënt wegen ruim op tegen de technische vereisten en de leercurve.
\end{abstract}

\section{INLEIDING}

Hoewel de exacte etiologie van maagdilatatie en torsie (MDT) nog onbekend is, zijn reeds vele predisponerende factoren geïdentificeerd. Vooral honden van grote en reuzenrassen worden getroffen. Duitse doggen, Duitse herders, standaardpoedels, bassethonden, chow chows en kruisingen van grote rassen hebben het grootste risico MDT te ontwikkelen (Glickman et al., 1994; Brockman et al., 1995; Evans et al., 2010). Het risico dat een hond van een groot of reuzenras tijdens zijn leven een episode van MDT ontwikkelt, bedraagt 21-40\% (Glickman et al., 2000b). Maagdilatatie en torsie komen vaker voor bij honden van middelbare en oudere leeftijd en teven worden vaker getroffen dan reuen. Tevens blijkt er een familiale predispositie te zijn (Glickman et al., 2000a). Andere predisponerende factoren zijn lichaamsbouw (honden met een diepe thorax), gedrag (gulzige eters), eten vanuit een verhoogde voederbak, stress (toilettage, hondenshows), voedsel met een korrelgrootte $<3 \mathrm{~cm}$, slechts één voederbeurt per dag, chronische ontstekingen van het maag-darmkanaal en een lang hepatogastrisch ligament (Schellenberg et al., 1994; Hall et al., 1995; Braun et al., 1996; Bredal, 1998; Elwood, 1998; Theyse et al., 1998; Glickman et al., 2000a; Glickman et al., 2000b). Hoewel in het verleden werd aangenomen dat een milttorsie of splenectomie de kans op MDT doet toenemen (Millis et al., 1995), konden Goldhammer et al. (2012) dit in een grotere, recente studie niet bevestigen.

Maagdilatatie en -torsie worden gekenmerkt door een dilatatie en een variabele graad van kanteling van de maag. De opstapeling van gas en vocht in de maag leidt tot circulatoire en respiratoire stoornissen. Indien niet onmiddellijk een accurate behandeling kan worden gestart, volgt onvermijdelijk de dood. Ondanks een gepaste medicamenteuze en chirugische interventie kan de mortaliteit oplopen van 15 tot 33\% (Brockman et al., 1995; Glickman et al., 1998). De initiële therapie bestaat uit de behandeling van de hypovolemische shock in combinatie met gastrische decompressie (sondage of punctie). Indien een torsie aanwezig is, volgt een chirurgische ingreep, zodra de patiënt cardiovasculair is gestabiliseerd (Glickman et al., 1998).

Wanneer na het reponeren van de maag een gastropexie wordt uitgevoerd, zodat de maag permanent aan de rechterbuikwand vastzit, daalt de kans op recidief van 54,5\% naar 4,3\% (Glickman et al., 1998). De gemiddelde overlevingstijd bij honden na een spoedoperatie voor MDT stijgt van 188 dagen naar 547 dagen in het geval een gastropexie werd uitgevoerd (Glickman et al., 1998).

Omwille van de hoge frequentie van MDT bij bepaalde rassen en vermits niet alle predisponerende factoren kunnen worden geëlimineerd, is het uitvoeren van preventieve chirurgie gerechtvaardigd. Bij rottweilers en Duitse doggen resulteert een profylactische gastropexie in respectievelijk een 2- en een 30-voudige afname van de mortaliteit (Ward et al., 2003). Deze ingreep kan worden uitgevoerd via een conventionele celiotomie of via laparoscopisch geassisteerde of laparoscopische technieken. Dit artikel geeft een overzicht van de verschillende, op dit ogenblik beschikbare technieken en gaat nader in op de voor- en nadelen van de minimaal invasieve methoden.

\section{CONVENTIONELE CELIOTOMIETECHNIEKEN}

\section{Circumcostale gastropexie}

Deze techniek bestaat uit het creëren van een seromusculaire weefselflap van de maag die doorheen een 


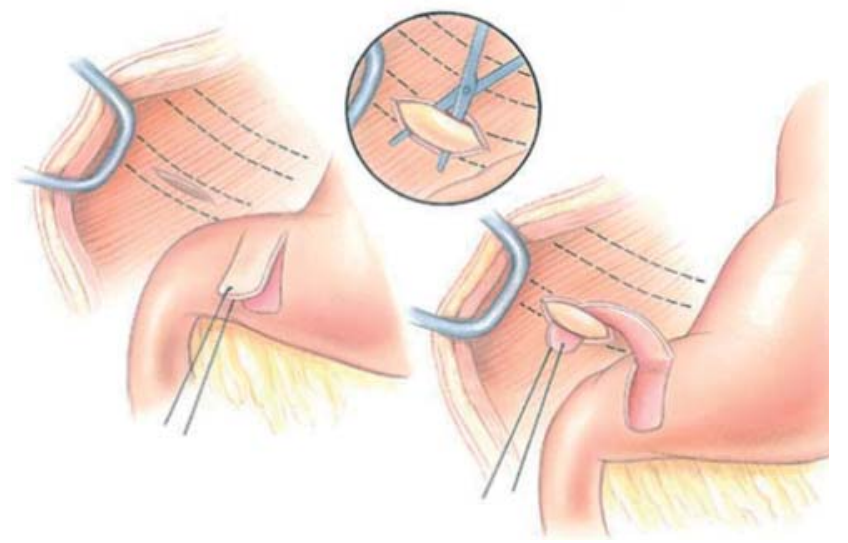

Figuur 1. Circumcostale gastropexie (uit Fossum, 2007).

tunnel achter de laatste rib wordt gebracht en nadien opnieuw wordt vastgehecht aan de maag (Figuur 1).

Er wordt een 3-5 cm lange incisie gemaakt doorheen de volledige dikte van de $\mathrm{m}$. transversus abdominis ter hoogte van de chondrocostale verbinding van de laatste volledige rib $\left(11^{\mathrm{e}}-12^{\mathrm{e}} \mathrm{rib}\right)$. Er dient voorzichtigheid te worden geboden om het diafragma niet te beschadigen en geen iatrogene pneumothorax te veroorzaken. Door middel van stompe dissectie wordt een tunnel achter de rib gecreëerd. Vervolgens worden twee parallelle, $4 \mathrm{~cm}$ lange incisies gemaakt op $3 \mathrm{~cm}$ van elkaar, doorheen de seromuscularis van het antrum pyloricum. De zone tussen de twee incisies wordt ondermijnd via stompe dissectie en door middel van een boogvormige incisie worden de craniale uiteinden van beide incisies met elkaar verbonden, waardoor een flap wordt gecreëerd. De flap wordt vervolgens craniodorsaal doorheen de tunnel onder de rib gebracht en opnieuw vastgehecht op zijn originele plaats. Een variatie op deze techniek maakt gebruik van een dubbele flap: de vrijgeprepareerde laag van de seromuscularis wordt middendoor geknipt en de twee flappen worden, na achter de rib te tunnelen, aan elkaar gehecht (Broome en Walsh, 2003; Fossum, 2007).

Modificaties van deze techniek bestaan uit het doorsnijden van het kraakbenig deel van de $10^{\mathrm{e}}-11^{\mathrm{e}}$ rib, waarbij het proximale uiteinde door een seromusculaire tunnel in het antrum pyloricum wordt gebracht en waarbij de uiteinden van de ribben dan terug aan elkaar worden vastgemaakt (Pope en Jones, 1999). Deze techniek is sneller en kan zonder assistentie worden uitgevoerd. Een andere modificatie minimaliseert de dissectie van de maagwand door gebruik te maken van de relatief losse verbinding tussen seromuscularis en submucosa/mucosa. De seromuscularis van de maag wordt stevig vastgegrepen en een $3 \mathrm{~cm}$ lange plooi van de maagwand wordt doorheen de tunnel achter de rib getrokken. Daarna worden drie tot vier incisies gemaakt in de seromuscularis aan beide zijden van de maagplooi zodat deze vervolgens aan elkaar kunnen worden gehecht (Degna et al., 2001).

Beschreven complicaties zijn peritonitis ten gevolge van perforatie van de maag (Woolfson en Kostolich, 1986), pneumothorax (Leib et al., 1985) en iatrogene ribfracturen (Rasmussen, 2003). De myo- elektrische activiteit van de maag en de maaglediging worden niet beïnvloed door deze techniek (Hall et al., 1992; Hall et al., 1997).

Circumcostale gastropexie resulteert in een zeer sterke connectie tussen de maag en de buikwand. Testen uitgevoerd 21 dagen na de operatie leverden een treksterkte van $109 \mathrm{~N}$ op (Fox et al., 1985). Er zijn tot op heden geen publicaties verschenen waarbij melding wordt gemaakt van recidieven van maagtorsie na circumcostale gastropexie. Wel beschreven Leib et al. (1985) 3\% (1/30) maagdilatatie na circumcostale gastropexie en Woolfson en Kostolich (1986) beschreven $6 \%(2 / 31)$ sterfte of euthanasie omwille van ernstige acute maagdilatatie. In beide gevallen werd niet bepaald of er ook een torsie aanwezig was.

\section{Belt-loop gastropexie}

Bij belt-loop gastropexie wordt de seromusculaire flap van de maagwand doorheen een tunnel in de buikwand gebracht (Figuur 2).

De pexieplaats bevindt zich 2-3 vingerdiktes caudaal van de laatste rib en in het onderste derde van de thoraxhoogte. Daar worden twee parallelle dorsoventrale incisies van 3-4 cm gemaakt in de $\mathrm{m}$. transversus abdominis op $2 \mathrm{~cm}$ van elkaar. Door middel van stompe dissectie tussen de twee incisies wordt een tunnel gecreëerd. Vervolgens wordt op analoge wijze als bij circumcostale gastropexie een flap gecreëerd ter hoogte van het antrum pyloricum. Deze flap wordt van caudaal naar craniaal doorheen de tunnel gebracht en vervolgens terug vastgehecht op zijn originele plaats

A
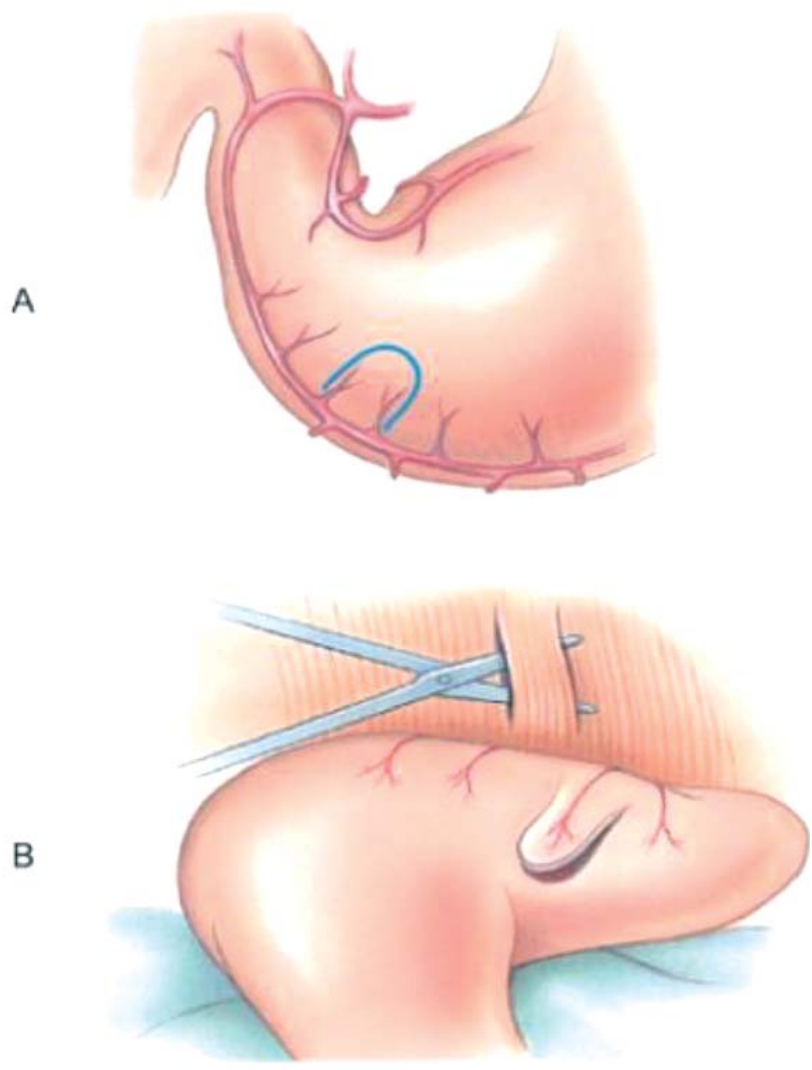

Figuur 2. Belt-loop gastropexie (uit Fossum, 2007). 
(Whitney et al., 1989). Deze techniek veroorzaakt geen belemmering van de normale peristaltische contracties van de maag (Whitney et al., 1989).

Een modificatie van de techniek bestaat uit het gebruik van huidnietjes in plaats van manueel te hechten (Coolman et al., 1999). Deze techniek werd even sterk bevonden maar is aanzienlijk sneller (tot $50 \%$ ). Belandria et al. (1999) beschreven een gelijkaardige techniek waarbij gebruik werd gemaakt van een gastro-intestinale anastomose (GIA)-stapler (United States Surgical Corporation, Norwalk, Connecticut).

Ernstige complicaties zijn zeldzaam. Iatrogene pneumothorax ten gevolge van accidentele incisie tot in de thoraxholte bij het creëren van de abdominale tunnel werd beschreven (Rasmussen, 2003).

De maximale treksterkte 50 dagen postoperatief werd bepaald op $109 \mathrm{~N}$ (Wilson et al., 1996). Bij geen enkele van de 60 honden uit drie gepubliceerde retrospectieve studies werd MDT gedetecteerd tijdens een follow-upperiode van 3-33 maanden (Schulman et al., 1986; Whitney et al., 1989; Belandria et al., 1999).

\section{Incisionele gastropexie}

Bij deze gastropexietechniek wordt een incisie gemaakt in de buikwand en in de maagwand die dan vervolgens aan elkaar worden gehecht (Figuur 3).

Deze technisch gemakkelijke procedure bestaat uit een 5-6 $\mathrm{cm}$ lange incisie doorheen de $\mathrm{m}$. transversus abdominis in de rechter ventrolaterale buikwand, loodrecht georiënteerd op de lengteas van de patiënt. Een even lange incisie wordt vervolgens gemaakt in de se-

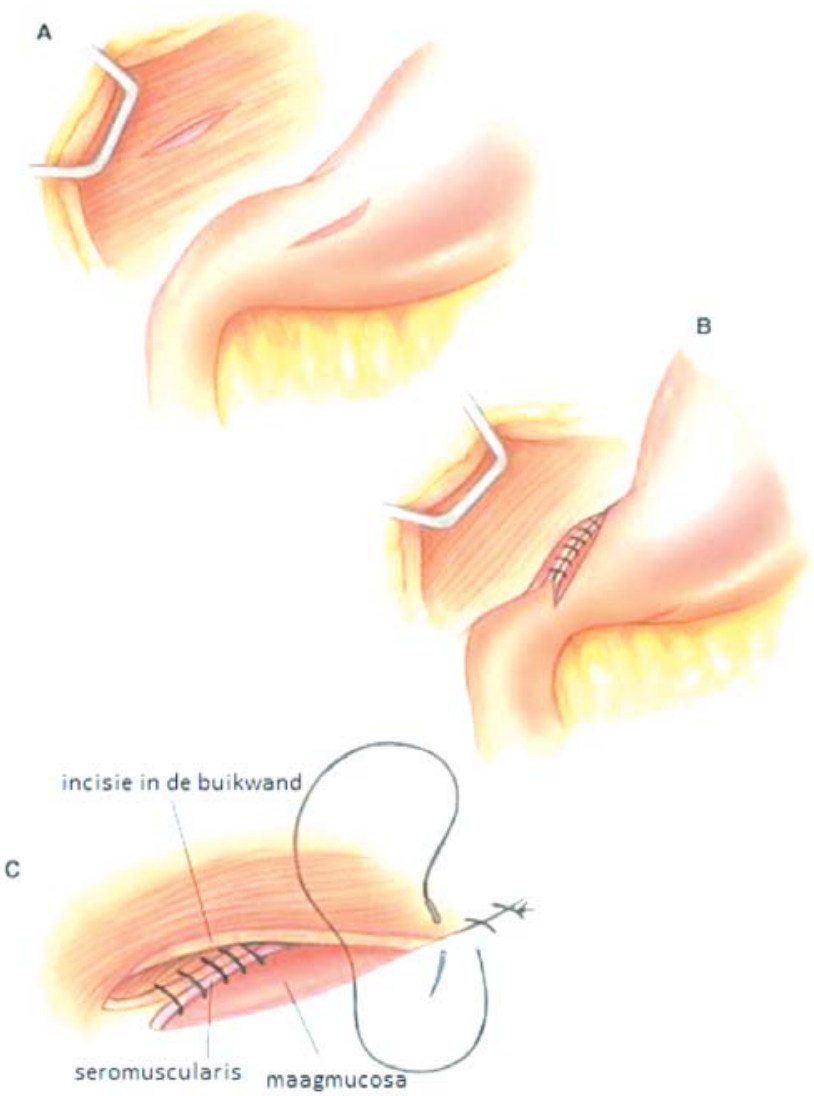

Figuur 3. Incisionele gastropexie (naar Fossum, 2007). romuscularis van de maagwand van het antrum pyloricum, halverwege tussen de curvatura major en minor. Beide randen van deze incisie worden doorlopend gehecht aan de tegenoverliggende randen van de incisie in de buikwand. Dit gebeurt van dorsaal naar ventraal en beginnend met de craniale randen (MacCoy et al., 1982). Complicaties, zoals accidentele penetratie van de maagmucosa en iatrogene pneumothorax, zijn zeldzaam indien deze ingreep deskundig wordt uitgevoerd (MacCoy et al., 1982; Hardie et al., 1996).

De gemiddelde treksterkte van deze techniek bedraagt $60-85 \mathrm{~N}$, afhankelijk van het postoperatieve tijdstip waarop de treksterkte werd bepaald (Fox et al., 1985; Hardie et al., 1996; Waschak et al., 1997). De frequentie van MDT bedraagt $0 \%(0 / 44)$ tot $4 \%(3 / 74)$ (MacCoy et al., 1982; Glickman et al., 1998).

\section{Sondegastropexie}

Wanneer een gastrotomiesonde in plaats van in de fundus (linkerbuikwand) in de pylorus wordt geplaatst (rechterbuikwand) dan verhinderen de hierdoor ontstane vergroeiingen kanteling van de maag (Figuur 4). Oorspronkelijk werd de percutane sonde beschreven als een snelle en simpele manier om na chirurgie voor MDT maagdecompressie te bekomen en om medicatie toe te dienen. De percutane tubegastropexie kan uiteraard ook worden uitgevoerd als een profylactische ingreep.

Via een steekincisie in de rechterbuikwand wordt een voedingssonde (bijvoorbeeld Foley-katheter) doorheen de maagwand tot in het maaglumen gebracht. De ballon van de katheter wordt opgeblazen en de maag wordt stevig tot tegen de buikwand getrokken door tractie op de katheter uit te oefenen. De sonde moet minstens 7-10 dagen ter plaatse blijven om permanente adhesie toe te laten.

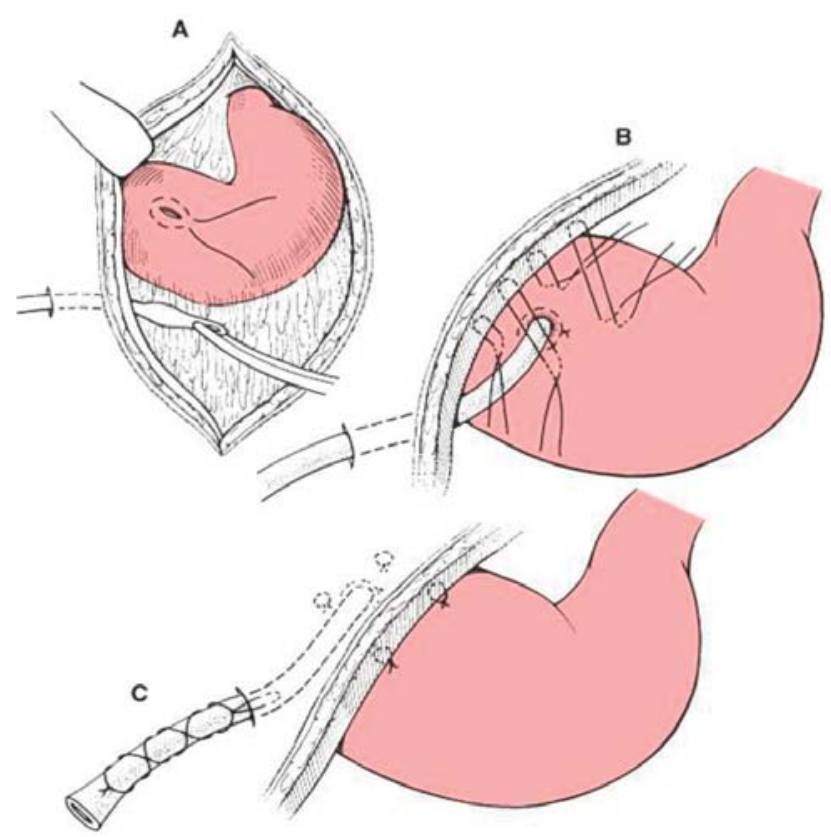

Figuur 4. Sondegastropexie (uit Fossum, 2007). 
Een modificatie bestaat erin de sonde via een celiotomie te plaatsen, zodat bijkomende hechtingen tussen de maagwand en de buikwand een goede adhesie verzekeren.

Wanneer de procedure ondeskundig wordt uitgevoerd, kan een lekkage van maaginhoud resulteren in peritonitis (Broome en Walsh, 2003; Fossum, 2007). Tevens is de morbiditeit bij deze techniek relatief hoog ten gevolge van een verstoorde myo-elektrische activiteit van de maagwand (Stampley et al., 1992; Hosgood, 1994).

In een experimentele studie waarbij de gastropexie via percutane plaatsing werd geëvalueerd 58 dagen na plaatsing van de sonde, werd slechts bij 57\% (4/7) een vergroeiïng tussen maag- en buikwand vastgesteld. De treksterkte van deze gastropexie bedroeg $22 \mathrm{~N}$ ten opzichte van $62 \mathrm{~N}$ bij de controlegroep waarbij een incisionele gastropexie werd uitgevoerd (Waschak et al., 1997). Sondegastropexie via laparotomie leverde een treksterkte van $63 \mathrm{~N}$ op (Johnson et al., 1984). Bij deze techniek werd de frequentie van MDT vastgesteld op 5-11\% (Johnson et al., 1984; Fox et al., 1985).

\section{Incorporerende gastropexie}

Deze eenvoudige en snelle methode bestaat uit het vasthechten van de maagwand aan de linea alba bij het sluiten van de buikwand (Figuur 5).

Het antrum pyloricum wordt over een lengte van mi-
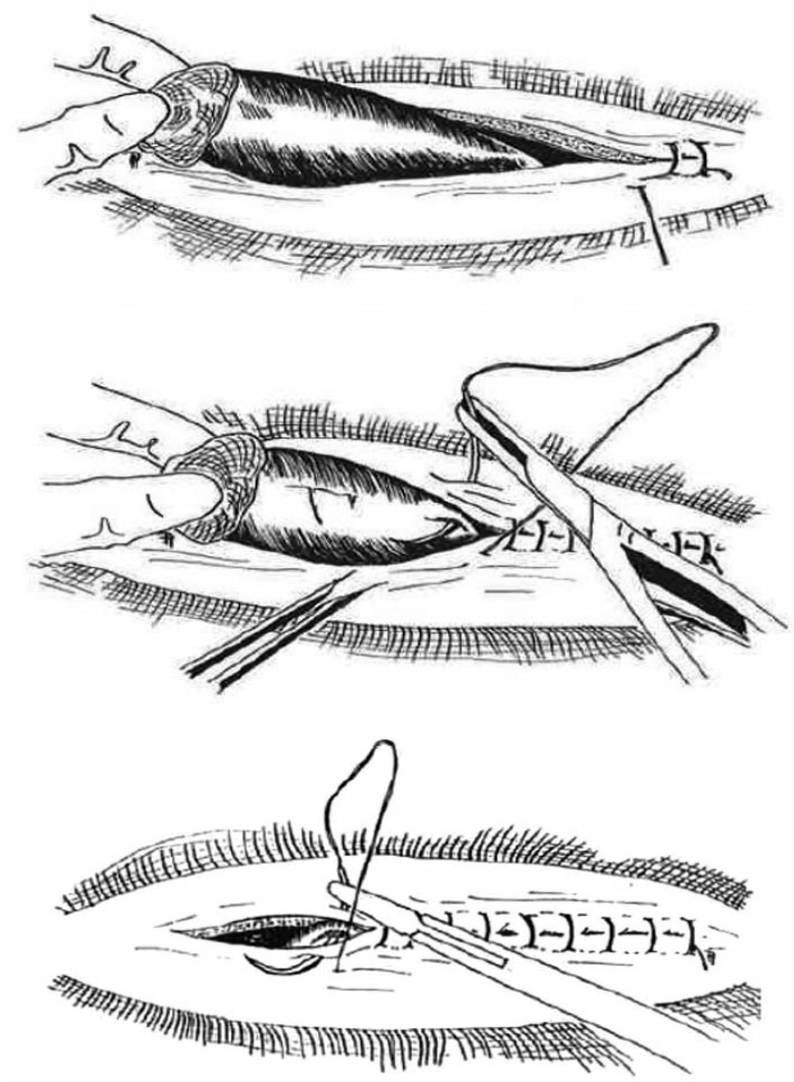

Figuur 5. Incorporerende gastropexie (naar Bojrab, 1998). nimum $5 \mathrm{~cm}$ geïncorporeerd in de doorlopende buikwandhechting, door het hechtmateriaal tussen twee steken in de randen van de linea alba doorheen de seromuscularis van de maag te brengen. Bij deze techniek wordt er dus geen incisie in de maagwand gemaakt (Meyer-Lindenberg et al., 1993).

De belangrijkste complicatie bij deze techniek is dat een volgende middenlijnincisie resulteert in het accidenteel openen van de maagwand. De stevigheid van de pexie is tevens minder betrouwbaar doordat geen incisies in de buikwand worden gemaakt. Om deze redenen wordt deze techniek niet echt aangeraden (Rasmussen, 2003; Fossum, 2007).

Er zijn geen studies beschikbaar die de treksterkte van de pexieplaats bepalen. Een grote retrospectieve studie bepaalt de kans op MDT op 6\% (4/63) (MeyerLindenberg et al., 1993).

\section{MINIMAAL INVASIEVE TECHNIEKEN}

\section{Endoscopisch geassisteerde gastropexie}

Doordat de maag via de endoscoop wordt gedilateerd en de juiste positie van het antrum intraluminaal wordt geverifieerd, kan de gastropexie via een minilaparotomie worden uitgevoerd (Figuur 6).

Bij deze techniek wordt de maag door middel van gas opgeblazen en wordt een gastroscoop gebruikt om de percutane plaatsing van steunhechtingen ter hoogte van het antrum pyloricum te begeleiden. De steunhechtingen worden vervolgens aangetrokken om de maag tot tegen de buikwand te brengen. Tussen de steunhechtingen wordt een incisie doorheen de huid, subcutis en buikwand gemaakt. Daarna wordt een longitudinale incisie van ongeveer $4 \mathrm{~cm}$ gemaakt doorheen de seromuscularis van het antrum pyloricum. De seromuscularis wordt vastgehecht aan de $\mathrm{m}$. transversus abdominis door middel van twee afzonderlijke doorlopende hechtingen, waarna de m. obliquus internus abdominis en m. obliquus externus abdominis doorlopend worden gesloten. De subcutis wordt doorlopend en de huid wordt intradermaal ge-

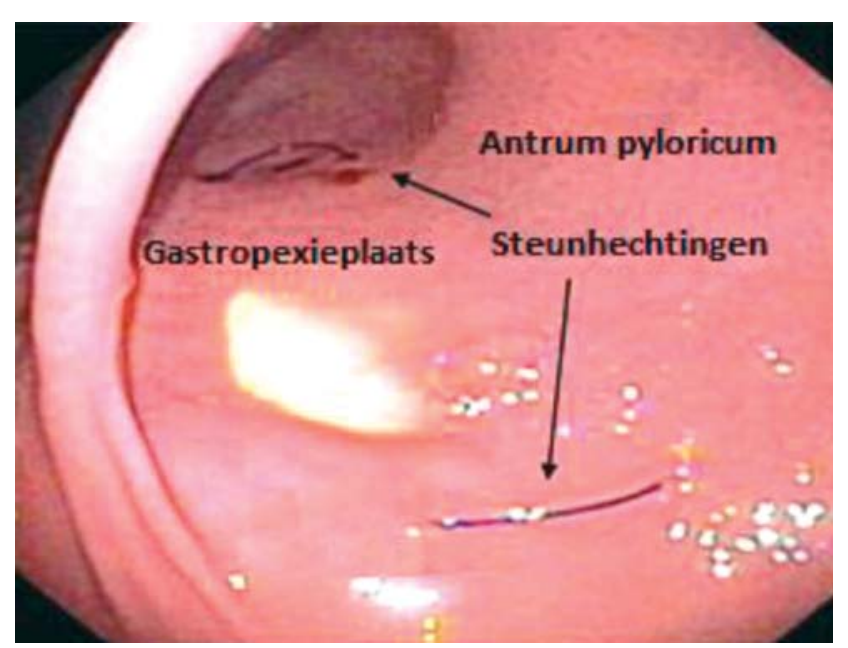

Figuur 6. Endoscopisch geassisteerde gastropexie (naar Dujowich, 2008). 
sloten. De gemiddelde duur van deze ingreep is 22 minuten (Dujowich et al., 2010).

Er worden geen ernstige complicaties gerapporteerd tijdens de ingreep. Milde gastro-intestinale klachten zoals braken en diarree treden op kort na de operatie, maar verdwijnen zonder behandeling. Een van de moeilijkheden bij deze ingreep is een voldoende caudale positie van de maag te bekomen om gastropexie achter de laatste rib mogelijk te maken (Dujowich et al., 2010).

Dujowich et al. (2010) bepaalden geen treksterkte na deze ingreep, maar veronderstelden een gelijkaardige treksterkte $(106,5 \pm 45,6 \mathrm{~N})$ als bepaald voor de laparoscopisch geassisteerde gastropexie. In een studie met 23 honden werd na een gemiddelde follow-upperiode van 1,4 jaar geen enkel optreden van MDT gerapporteerd.

\section{Laparoscopisch geassisteerde gastropexie (met mini- laparotomie)}

Via laparoscopie wordt de pylorus geïdentificeerd en doorheen een minilaparotomie tegen de rechterbuikwand getrokken (Figuur 7).

$\mathrm{Na}$ het plaatsen van een trocart/canule $2-3 \mathrm{~cm}$ caudaal van de umbilicus en het creëren van een pneumoperitoneum $(8 \mathrm{mmHg})$ wordt een 5 of $10 \mathrm{~mm}$ laparoscoop ingebracht. Een tweede canule van $10 \mathrm{~mm}$ wordt ter hoogte van de pexieplaats ingebracht $(3 \mathrm{~cm}$ caudaal van de laatste rib en lateraal van de $\mathrm{m}$. rectus abdominis). Via de instrumentencanule wordt het antrum pyloricum vastgegrepen met behulp van een laparoscopische Babcock-weefselklem. Door de klem en canule terug te trekken wordt het antrum pyloricum tegen de buikwand gebracht. De canuleopening wordt, parallel met de laatste rib, verlengd tot een minilaparotomie (ongeveer $4 \mathrm{~cm}$ ). Doorheen de seromuscularis van de maag wordt eenzelfde incisie gemaakt en zoals hoger vermeld wordt de maagwandincisie aan de $\mathrm{m}$. transversus abdominis gefixeerd. De mm. obliquus internus en externus abdominis, subcutis en huid worden routinematig gesloten (Rawlings et al., 2001; Rawlings et al., 2002; Rawlings, 2002).

De acht honden uit de oorspronkelijke studie van Rawlings et al. (2001) ontwikkelden slechts milde postoperatieve complicaties en geen van ze had gastrointestinale klachten gedurende een follow-upperdiode van één maand na de operatie. Een andere studie rapporteerde daarentegen volgende complicaties: de vorming van huidplooien ter hoogte van de gastropexieplaats onmiddellijk na de operatie $(47 \%)$, seromavorming ter hoogte van de gastropexie $(6 \%)$ en iatrogene perforatie van het miltkapsel bij het plaatsen van de trocart (12\%) (Urbanová et al., 2011). In geval van iatrogeen milttrauma kan de bloeding meestal worden gestopt met zachte compressie met een atraumatisch instrument. In sommige gevallen echter treedt een ernstige bloeding op die conversie naar conventionele celiotomie vereist (Urbanová et al., 2011). Een ander mogelijk probleem tijdens een laparoscopische procedure wordt veroorzaakt door het omentum dat

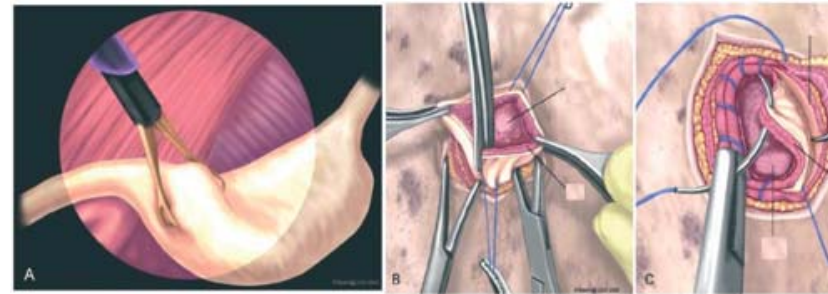

Figuur 7. Laparoscopisch geassisteerde gastropexie met minilaparotomie (uit Rawlings, 2001).

rond de maag komt te liggen. Dit kan worden opgelost door het omentum vast te grijpen en weg te trekken met een atraumatische klem (Urbanová et al., 2011). Bij obese dieren is een laparoscopische of laparoscopisch geassisteerde procedure vaak moeilijker uit te voeren door grote hoeveelheden vetweefsel in de buikholte (Urbanová et al., 2011).

Een positieve contraststudie uitgevoerd 25 dagen na de ingreep toonde een normale positie van de maag en normale maaglediging aan. De ultieme treksterkte bedroeg $107 \pm 46 \mathrm{~N}$ (Rawlings et al., 2001). In een andere studie waarbij deze techniek bij 23 honden werd toegepast, trad geen MDT op gedurende een followupperiode van één jaar (Rawlings et al., 2002).

\section{Laparoscopisch geassisteerde gastropexie (zonder minilaparotomie)}

Nadat de maagwand via laparoscopische technieken tot tegen de buikwand wordt getrokken wordt deze met percutane hechtingen gefixeerd.

Er wordt een pneumoperitoneum gecreëerd. De cameracanule wordt net caudaal van de umbilicus geplaatst en de twee instrumentencanules worden $6-7 \mathrm{~cm}$ craniaal en caudaal van de umbilicus ingebracht. Het antrum pyloricum wordt vastgegrepen en tot tegen de pexieplaats op de rechter ventrale buikwand gebracht ( $3 \mathrm{~cm}$ caudaal van de $13^{\mathrm{e}}$ rib en 3-4 cm lateraal van $\mathrm{m}$. rectus abdominis). Het peritoneum ter hoogte van de pexieplaats en de serosa van de maagwand ter hoogte van het antrum worden beschadigd door middel van een monopolaire elektrocoagulatiehaak. Door middel van transilluminatie vanuit het abdomen wordt de pexieplaats aan de buitenzijde geïdentificeerd en wordt een huidincisie gemaakt. Er worden vier hechtingen geplaatst doorheen de intacte buikwand en seromuscularis van de maag (Figuur 8). De huid en subcutis worden gesloten over de subcutaan verzonken pexiehechtingen. De canuleopeningen worden routinematig gesloten. De gemiddelde operatieduur wordt geschat op 40 minuten (Mathon et al., 2009).

Een mogelijke complicatie van deze techniek is accidentele penetratie van het hechtmateriaal doorheen de maagmucosa (Mathon et al., 2009). Bij radiografische controle na tien weken worden slechts milde veranderingen in de maaglediging gezien (Mathon et al., 2009).

De maximale treksterkte zoals bepaald tien weken na de operatie bedraagt 51,1 $\pm 16,4 \mathrm{~N}$ (Mathon et al., 2009). 

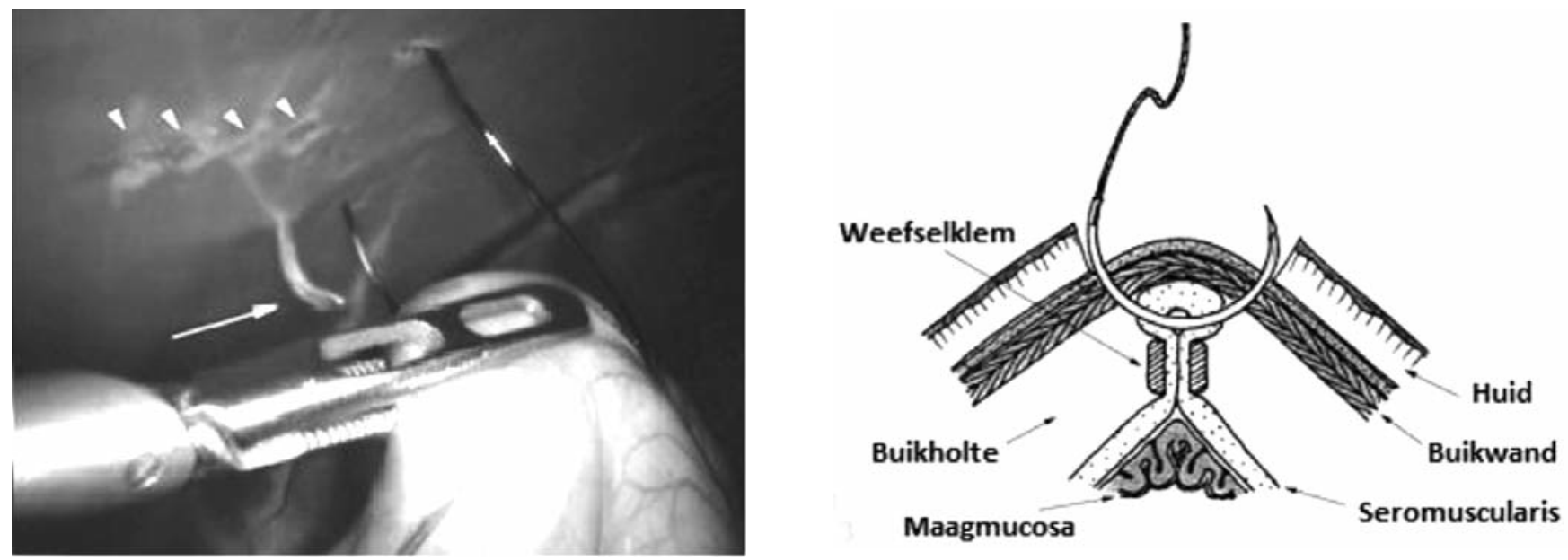

Figuur 8. Laparoscopisch geassisteerde gastropexie zonder minilaparotomie (naar Mathon, 2009).

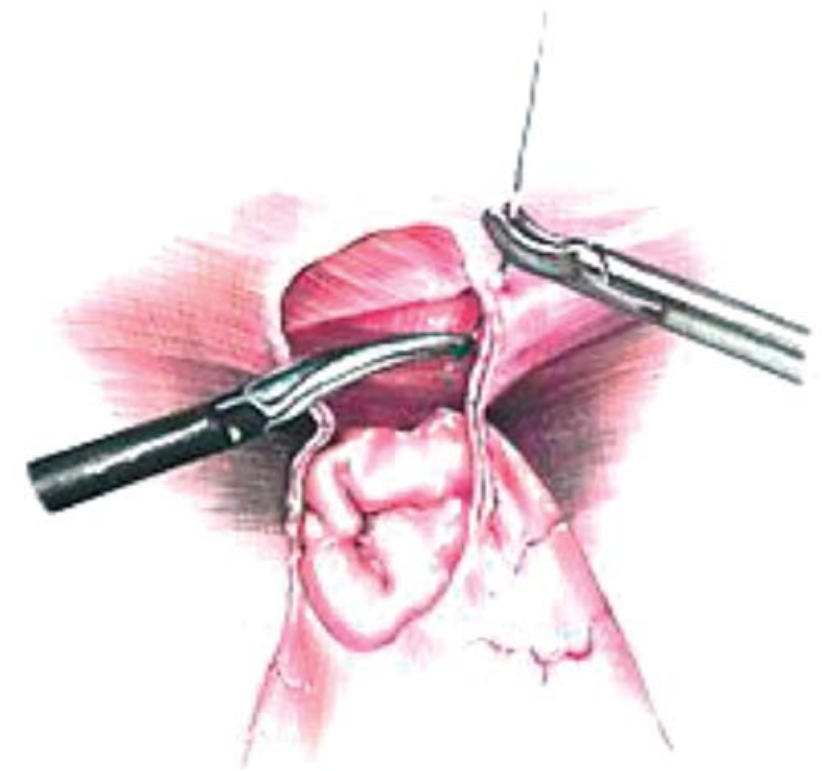

Figuur 9. Laparoscopische gastropexie met intracorporale hechttechniek (uit Sanchez-Margallo, 2007).

\section{Laparoscopische gastropexie (intracorporaal hechten)}

Mayhew en Brown (2009) beschreven een volledig laparoscopisch uitgevoerde gastropexie gebaseerd op een intracorporale hechttechniek (Figuur 9).

Bij deze techniek worden drie canules in de middenlijn geplaatst. De caudale instrumentencanule net caudaal van de umbilicus, de craniale instrumentencanule 3-4 cm caudaal van het xifoïd en de cameracanule ertussen in. De incisies (in de buikwand en maagwand) worden gemaakt met een laparoscopische dissectieschaar. Hechtmateriaal van circa $30 \mathrm{~cm}$ wordt doorheen een canule of percutaan ingebracht en wordt gebruikt om de incisie in de $\mathrm{m}$. transversus abdominis met twee laparoscopische naaldhouders vast te hechten aan de incisie in het antrum pyloricum. Mayhew en Brown (2009) stelden vast dat het eenvoudiger is om de tweede zijde van de gastropexie te hechten wanneer de incisies horizontaal georiënteerd zijn in plaats van verticaal. De gemiddelde gastropexietijd via deze procedure bedraagt 48 minuten (Mayhew en Brown, 2009).
Mayhew en Brown (2009) beschreven ook een modificatie van de laparoscopische gastropexietechniek gebruikmakend van een suture assist device (Endostitch, Autosuture, United States Surgical Corporation, Norwalk, Connecticut). Bij deze laparoscopische hechttechniek wordt gebruik gemaakt van een naald die alternerend in één van de zijden van de bek van de naaldhouder wordt vastgeklemd. Op deze manier kan het hechtmateriaal doorheen het weefsel worden gebracht, wanneer weefsel tussen de klauwen van het toestel wordt geplaatst. Op een gelijkaardige manier kunnen met dit toestel knopen worden aangelegd. De rest van deze procedure verloopt op dezelfde manier als de manuele hechttechniek. De gemiddelde gastropexietijd bedraagt 56 minuten.

Er worden geen ernstige intraoparatieve of postoperatieve complicaties gerapporteerd. Intracorporaal hechten is technisch moeilijk en vereist een optimaal instrumentarium. Ook de draadlengte moet zorgvuldig worden gekozen. Een te grote lengte werkt verwarrend en bemoeilijkt het hechten en leggen van knopen (Mayhew en Brown, 2009).

Honden die een laparoscopische gastropexie ondergaan, zijn duidelijk actiever in de postoperatieve periode dan honden die een laparoscopisch geassisteerde gastropexie ondergaan (Mayhew en Brown, 2009). De treksterkte van deze techniek en de kans op MDT werden nog niet bepaald.

\section{Laparoscopische gastropexie (intracorporale sta- pling)}

De gastropexie wordt zuiver laparoscopisch uitgevoerd en beide incisies worden met een stapler met elkaar verbonden (Figuur 10).

Tijdens deze ingreep wordt met behulp van een laparoscopische dissectieschaar een tunnel van 2 op 5 $\mathrm{cm}$ gemaakt in het ventrale deel van het antrum pyloricum. Een gelijkaardige tunnel wordt vervolgens gemaakt tussen de $\mathrm{m}$. transversus abdominis en de $\mathrm{m}$. abdominis obliquus internus ter hoogte van de pexieplaats. Om de de maag vast te maken aan de rechterbuikwand wordt een endo GIA stapler (United States Surgical Corporation, Norwalk, Connecticut) gebruikt 


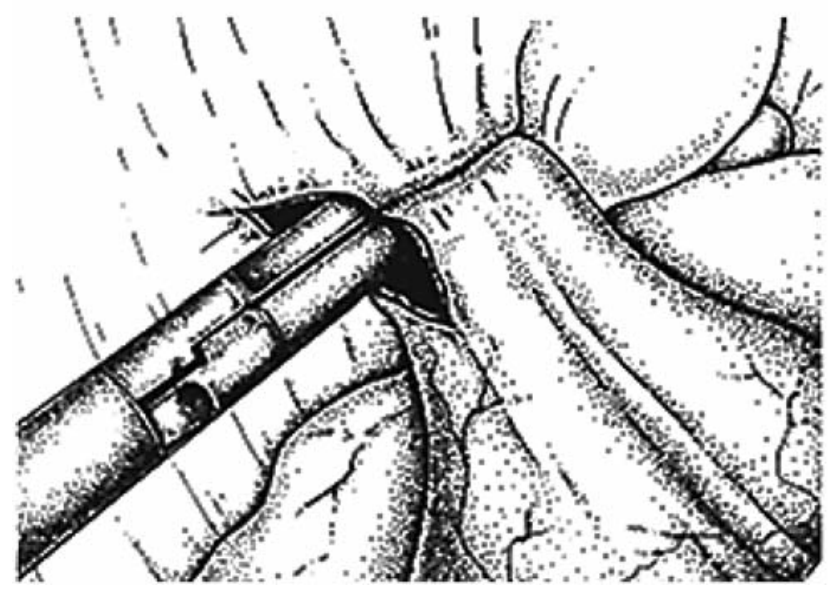

Figuur 10. Laparoscopische gastropexie met intracorporaal nieten (uit Hardie, 1996).

die zes rijen huidnietjes afvuurt en vervolgens snijdt tussen de twee middenste rijen. Nadien wordt een laparoscopische hernia stapler gebruikt om de tunnelopening te sluiten met drie tot zes individueel afgevuurde huidnietjes. De gemiddelde operatieduur van deze procedure bedraagt 130 minuten (Hardie et al., 1996).

Mogelijke complicaties zijn maagperforatie (2/14), milttrauma (2/14) en subcutaan emfyseem (4/14). De gemiddelde treksterkte na zeven dagen bedraagt $45 \mathrm{~N}$ en na dertig dagen $72 \mathrm{~N}$ (Hardie et al., 1996).

Sanchez-Margallo et al. (2007) beschreven een modificatie waarbij huidnietjes en het intracorporaal hechten worden gecombineerd. Ter hoogte van het antrum pyloricum en in de rechterbuikwand net caudaal van de laatste rib wordt een seromusculaire tunnel gecreëerd. De twee tunnels worden tot tegen elkaar gebracht en aan elkaar vastgemaakt met een stapler. Het overblijvende stoma na de anastomose van de twee tunnels wordt gesloten met intracorporale enkelvoudige hechtingen. De gemiddelde duur van deze techniek is 73 minuten Tot nog toe werden er met deze techniek geen intraoperatieve moeilijkheden of postoperatieve complicaties gerapporteerd.

\section{DISCUSSIE}

Gastropexie is een effectieve maatregel in het voorkomen van MDT (Glickman et al., 1998; Ward et al., 2003). De ideale gastropexie is snel, technisch gemakkelijk uit te voeren, zonder intra- of postoperatieve complicaties, leidt tot een permanente verbinding tussen maag en buikwand in een anatomische positie zodat de maag niet meer kan roteren en beïnvloedt daarbij de maaglediging niet (Rawlings et al., 2001). Om een permanente verbinding te bekomen, moet de muscularis van de maag contact maken met de buikspieren. Een intacte serosa vormt immers geen permanente adhesies op een intact peritoneum (Fossum, 2007). Daartoe moeten het peritoneum evenals de sersosa van de maag worden verwijderd, thermisch beschadigd of ingesneden (Fossum, 2007). Om voldoende contact te bekomen, moet de gastropexie minstens $3 \mathrm{~cm}$ lang zijn (Dujowich et al., 2010). De ideale leeftijd om een profylactische gastropexie uit te voeren, bedraagt 6-8 maanden (Monnet, 2003). De ingreep kan gelijktijdig met een ovariëctomie of met een exploratieve laparotomie gebeuren (Monnet, 2003).

De drie meest aanbevolen conventionele technieken zijn incisionele, circumcostale en belt-loop gastropexie. Circumcostale en belt-loop gastropexie reduceren de kans op MDT tot 0-6\% (Leib et al., 1985; Schulman et al., 1986; Woolfson en Kostolich, 1986; Whitney et al., 1989) en beide resulteren in een sterke adhesie van het antrum pyloricum aan de buikwand (109 N) (Fox et al., 1985; Wilson et al., 1996). Deze technieken zijn echter technisch moeilijk uit te voeren en mogelijke complicaties zijn iatrogene pneumothorax, ribfracturen en peritonitis (Woolfson en Kostolich, 1986; Leib et al., 1985; Rasmussen, 2003). De complicaties zijn echter zeldzaam indien de ingreep wordt uitgevoerd door een ervaren chirurg. Hoewel de incisionele techniek resulteert in een minder hoge treksterkte (60-85 N) (Fox et al., 1985; Hardie et al., 1996; Waschak et al., 1997), verdient deze techniek volgens de meeste chirurgen toch de voorkeur omwille van de reductie van MDT (0-4\%) en de lage morbiditeit (MacCoy et al., 1982; Glickman et al., 1998). Wegens het risico op accidentele perforatie van de maag bij een volgende celiotomie wordt de incorporerende gastropexie afgeraden, tenzij een abrupte beëindiging van de anesthesie zou vereist zijn. De sondegastropexie wordt afgeraden wegens het hogere voorkomen van MDT (5-11\%) (Johnson et al., 1984; Fox et al., 1985) en de verstoorde myo-elektrische activiteit van de maag (Stampley et al., 1992; Hosgood, 1994). Dit laatste is vermoedelijk te wijten aan het feit dat bij deze techniek alle lagen van de maagwand worden ingesneden.

De traditionele technieken vereisen een celiotomie met de bijhorende risico's inzake morbiditeit en mortaliteit. Om deze risico's te verminderen, hebben verscheidene onderzoekers minimaal invasieve technieken ontwikkeld om een gastropexie uit te voeren. Sommige technieken zijn endoscopisch of laparoscopisch geassisteerd terwijl andere volledig laparoscopisch zijn. De voordelen van deze technieken zijn kleinere operatieincisies met minder bloedverlies, minder postoperatieve pijn, een cosmetisch mooier resultaat, een kortere hospitalisatieduur en een vluggere recovery (Dujowich et al., 2010; Urbanová et al., 2011).

De endoscopisch geassisteerde gastropexie blijkt een uitstekend alternatief te zijn voor de laparoscopisch geassisteerde techniek om een permanente adhesie van de maag aan de buikband te creëren (Dujowich et al., 2010). Deze techniek vereist slechts één incisie in plaats van twee incisies bij een laparoscopisch geassisteerde gastropexie. Een ander voordeel ten opzichte van de andere minimaal invasieve technieken is dat het vereiste endoscopische instrumentarium in veel praktijken aanwezig is, wat mogelijk minder het geval is voor laparoscopisch materiaal.

Hoewel laparoscopisch en endoscopisch geassisteerde technieken reeds minder invasief zijn dan de open celiotomietechnieken vereisen ze een incisie 
doorheen de buikspieren, wat pijnlijker is dan een incisie ter hoogte van de linea alba (Mayhew en Brown, 2009). De volledig laparoscopische technieken mogen dan technisch moeilijker uit te voeren zijn, ze zijn geassocieerd met een duidelijke daling van wondcomplicaties en met een verminderde recoveryduur (Mayhew en Brown, 2009). Een ander groot voordeel van de laparoscopische benadering is de mogelijkheid om de meeste intra-abdominale organen te beoordelen zonder de incisie te moeten vergroten en daarbij de mogelijkheid om ook biopten te nemen in geval van pathologische bevindingen (Urbanová et al., 2011). Het enige nadeel van deze procedures is de nood aan dure laparoscopische instrumenten en de toegenomen operatieduur. Het gebruik van staplers of een sutureassist device leidt verrassend genoeg niet tot een verminderde operatietijd (Hardie et al., 1996; Mayhew en Brown, 2009). Hoewel de laparoscopische procedures langer duren, leiden oefening en ervaring tot een duidelijke daling van de operatieduur (Dujowich et al., 2010).

De gemiddelde treksterkte van een gastropexie aan de hand van minimaal invasieve technieken $(51-72 \mathrm{~N})$ is lager dan de treksterkte bekomen met de celiotomietechnieken (Hardie et al., 1996; Mayhew and Brown, 2009; Mathon et al., 2009). Enige voorzichtigheid dient echter aan de dag te worden gelegd bij de interpretatie van deze resultaten. In de verschillende studies die de treksterkte van een gastropexie onderzochten, werden de testen immers op verschillende tijdstippen na de operatie uitgevoerd en werd eveneens verschillend hechtmateriaal gebruikt (resorbeerbaar en niet-resorbeerbaar) wat mogelijk de resultaten beïnvloedde. Bovendien werd de sterkte van de adhesie nodig om maagtorsie te voorkomen tot op heden nog niet bepaald. Tevens is de treksterkte niet gecorreleerd aan klinische efficaciteit in de vorm van een reductie in het voorkomen van MDT (Rawlings et al., 2001).

Minimaal invasieve technieken kunnen over de hele lijn worden beschouwd als een goed alternatief voor de open celiotomiegastropexieën. Hoewel deze technieken worden geassocieerd met een langere leercurve en langere operatieduur, hebben verschillende studies hun voordeel aangetoond inzake recidieven, postoperatieve complicaties en comfort van de patiënt. Het gebruik van trainingsimulatoren en een doorgedreven opleiding worden dan ook ten zeerste aangeraden om de chirurgische vaardigheden te verbeteren en zo de tijd nodig om een minimaal invasieve profylactische gastropexie uit te voeren te reduceren, zodat de laparoscopische gastropexie in de toekomst de nieuwe gouden standaard kan worden.

\section{LITERATUUR}

Belandria G.A., Pavletic M.M., Boulay J.P., Penninck D.G., Schwarz L.A. (2009). Gastropexy with an automatic stapling instrument for the treatment of gastric dilatation and volvulus in 20 dogs. The Canadian Veterinary Journal 50, 733-740.
Braun L., Lester S., Kuzma A.B., Hosie S.C. (1996). Gastric dilatation-volvulus in the dog with histological evidence of preexisting inflammatory bowel disease: a retrospective study of 23 cases. Journal of the American Animal Hospital Association 32, 287-290.

Bredal W.P. (1998). Pneumonyssoides caninum infectiona risk factor for gastric dilatation-volvulus in dogs. Veterinary Research Communications 22, 225-231.

Brockman D.J., Washabau R.J., Drobatz K.J. (1995). Canine gastric dilatation/volvulus syndrome in a veterinary critical care unit: 295 cases (1986-1992). Journal of the American Veterinary Medical Association 207, 460-464.

Broome C.J., Walsh V.P. (2003). Gastic dilatation-volvulus in dogs. New Zealand Veterinary Journal 51, 275-283.

Caywood D., Teague H.D., Jackson D.A., Levitt M.D., Bond J.H. Jr. (1977). Gastric gas analysis in the canine gastric dilatation-volvulus syndrome. Journal of the American Animal Hospital Association 13, 459-62.

Coolman E.R., Manfra Marretta S., Pijanowski G.J., Coolman S.L. (1999). Evaluation of a skin stapler for belt-loop gastropexy in dogs. Journal of the American Animal Hospital Association 35, 440-444.

Degna M.T., Formaggini L., Fondati A., Assin R. (2001). Using a modified gastropexy technique to prevent recurrence of gastric dilatation-volvulus in dogs. Veterinary Medicine 96, 39-50.

Dujowich M., Keller M.E., Reimer S.B. (2010). Evaluation of short- and long-term complications after endoscopically assisted gastropexy in dogs. Journal of the American Veterinary Medical Association 236, 177-182.

Elwood CM. (1998). Risk factors for gastric dilatation in Irish setter dogs. Journal of Small Animal Practice 39, 185-190.

Evans K.T., Adams V.J. (2010). Mortality and morbidity due to gastric dilatation-volvulus syndrome in pedigree dogs in the UK. Journal of Small Animal Practice 51, 376-381.

Fossum T.W., Hedlund C.S. (2007). Surgery of the stomach. In: Fossum T.W. (editor). Small Animal Surgery. 3th Edition, Missouri, USA, Mosby Elsevier, p. 409-433.

Fox S.M., Ellison G.W., Miller G.J. (1985). Observation on the mechanical failure of three gastropexy techniques. Journal of the American Animal Hospital Association 21, 729-734.

Glickman L.T., Glickman N.W., Pérez C.M., Schellenberg D.B., Lantz G.C. (1994). Analysis of risk factors for gastric dilatation and dilatation-volvulus in dogs. Journal of the American Veterinary Medical Association 204, 14651471.

Glickman L.T., Glickman N.W., Schellenberg D.B., Simpson K., Lantz G.C. (1997). Multiple risk factors for the gastric dilatation-volvulus syndrome in dogs: a practitioner/owner case-control study. Journal of the American Animal Hospitalisation Association 33, 197-204.

Glickman L.T., Lantz G.C. , Schellenberg D.B., Glickman N.W. (1998). A prospective study of survival and recurrence following the acute gastric dilatation-volvulus syndrome in 136 dogs. Journal of the American Hospital Association 34, 253-259.

Glickman L.T., Glickman N.W.., Schellenberg D.B., Raghavan M, Lee T.L. (2000a). Incidence of and breed-related risk factors for gastric dilatation-volvulus in dogs. Journal of the American Veterinary Medical Association 216, 40-45.

Glickman L.T., Glickman N.W., Schellenberg D.B., Raghavan M., Lee T. (2000b). Non-dietary risk factors for gas- 
tric dilatation-volvulus in large and giant breed dogs. Journal of the American Veterinary Medical Association 217, 1492-1499.

Goldhammer M.A., Haining H., E.M. Milne, Shaw D.J., Yool D.A. (2012). Assessment of the incidence of GDV following splenectomy in dogs. Journal of Small Animal Practice 51, 23-28.

Hall J.A., Willer R.L., Seim H.B. III, Lebel J.R., Twedt D.C. (1992). Gastric emptying of nondigestible radiopaque markers after circumcostal gastropexy in clinically normal dogs and dogs with gastric dialation-volvulus. American Journal of Veterinary Research 53, 1961-1965.

Hall J.A., Willer R.L., Seim H.B., Powers B.E. (1995). Gross and histologic evaluation of hepatogastric ligaments in clinically normal dogs and dogs with gastric dilatation-volvulus. American Journal of Veterinary Research 56, 1611-1614.

Hall J.A., Willer R.L., Solie T.N., Twedt D.C. (1997). Effect of circumcostal gastropexy on gastric myoelectric and motor activity in dogs. Journal of Small Animal Practice 38, 200-207.

Hardie R.J., Flanders J.A., Schmidt P., Credille K.M., Pedrick T.P., Short C.E. (1996). Biomechanical and histological evaluation of a laparoscopic stapled gastropexy technique in dogs. Veterinary Surgery 25, 127-133.

Hosgood G. (1994). Gastric dilatation-volvulus in dogs. Journal of the Veterinary Medical Association 204, 17421747.

Johnson R.G., Barrus J., Greene R.W. (1984). Gastric dilatation-volvulus: recurrence rate following tube gastropexy. Journal of the American Animal Hospital Association 20, 33-37.

Komtebedde J., Guilford W.G., Haskins S.C., Higgins R.J., Snyder J.R. (1990). Surface oxygen tension $\left(\mathrm{PsO}_{2}\right)$ of splanchnic viscera (SV) in experimental gastric dilatation volvulus (GDV). Veterinary Surgery 19, 70-70.

Leib MS, Konde L.J., Wingfield W.E., Twedt D.C. (1985). Circumcostal gastropexy for preventing recurrence of gastric dilatation-volvulus in the dog: An evaluation of 30 cases. Journal of the American Veterinary Medical Association 187, 245-248.

MacCoy D.M., Sykes G.P., Hoffer R.E., Harvey H.J. (1982). A gastropexy technique for permanent fixation of the pyloric antrum. Journal of the American Hospital Association 18, 763-768.

Mayhew P.D., Brown D.C. (2009). Prospective evaluation of two intracorporeally sutured prophylactic laparoscopic gastropexy techniques compared with laparoscopic-assisted gastropexy in dogs. Veterinary Surgery 38, 738746.

Mathon D.H., Dossin O., Palierne S., Cremoux M., Rodriquez H., Meynaud-Collard P., Steiner J.M., Suchodolski J.W., Lefebvre H.P., Autefage A. (2009). A Laparoscopic-sutured gastropexy technique in dogs: mechanical and functional evaluation. Veterinary Surgery 38, 967-974.

Meyer-Lindenberg A., Harder A., Fehr M., Luerssen D., Brunnberg L. (1993). Treatment of gastric dilatationvolvulus and a rapid method for prevention of relapse in dogs: 134 cases (1988-1991). Journal of the American Veterinary Medical Association 203, 1303-1307.

Millis D.L., Nemzek J., Riggs C., Walshaw R.d (1995). Gastric dilatation-volvulus after splenic torsion in two dogs. Journal of the American Veterinary Medical Association 207, 314-315.
Monnet E. (2003). Gastric dilatation-volvulus syndrome in dogs. The Veterinary Clinics of North America. Small Animal Practice 33, 987-1005.

Pope E.R., Jones B.D. (1999). Clinical evaluation of a modified circumcostal gastropexy in dogs. Journal of the American Veterinary Medical Association 215, 952-955.

Rasmussen, LM. (2003). Stomach. In: Slatter D. (editor). Textbook of Small Animal Surgery. $3^{\text {th }}$ Edition, Saunders, Philadelphia, USA, p 592-640.

Rawlings C.A., Foutz T.L., Mahaffey M.B., Howerth E.W., Bement S., Canalis C. (2001). A rapid and strong laparoscopic-assisted gastropexy in dogs. American Journal of Veterinary Research 62, 871-875.

Rawlings C.A. (2002). Laparoscopic-assisted gastropexy. Journal of the American Animal Hospital Association 38, 15-19.

Rawlings C.A., Mahaffey M.B., Bement S., Canalis. C. (2002). Prospective evaluation of laparoscopic-assisted gastropexy in dogs susceptible to gastric dilatation. Journal of the American Veterinary Medical Association 221, 1576-1581.

Sanchez-Margallo F.M., Diaz-Güemes I., Usón-Gargallo J. (2007). Intracorporeal suture reinforcement during laparoscopic gastropexy in dogs. Veterinary Record 160, 806-807.

Schellenberg D., Yi Q., Glickman N.W., Glickman .LT. (1994). Influence of thoracic conformation and genetics on the risk of gastric dilatation-volvulus in Irish setters. Journal of the American Animal Hospital Association 34, 64-73.

Schulman A.J., Lusk R., Ettinger S.J., Lippincott C.L. (1986). Muscular flap gastropexy: a new surgical technique to prevent recurrences of gastric dilatation-volvulus syndrome. Journal of the American Animal Hospital Association 22, 339-346.

Stampley A.R., Burrows C.F., Ellison G.W., Tooker J. (1992). Gastric myoelectric activity after experimental gastric dilatation-volvulus and tube gastrostomy in dogs. Veterinary Surgery 21, 10-14.

Theyse L.F., van de Brom W.E., van Sluijs F.J. (1998). Small size of food particles and age as risk factors for gastric dilatation volvulus in Great Danes. The Veterinary Record 143, 48-50.

Urbanová L., Crha M., Raušer P., Nečas A. (2011). Clinical results and complications of preventive laparoscopic assisted gastropexy in 17 dogs: preliminary study. Acta Veterinaria 80, 93-99.

Wacker C.A., Weber U.T., Tanno F., Lang J. (1998). Ultrasonographic evaluation of adhesion induced by incisional gastropexy in 16 dogs. The Journal of Small Animal Practice 39, 379-384.

Ward M.P., Patronek G.J., Glickman L.T. (2003). Benefits of prophylactic gastropexy for dogs at risk of gastric dilatation-volvulus. Preventive Veterinary Medicine 60, 319329.

Waschak M.J., Payne J.T., Pope E.R., Jones B.D., WagnerMann C.C. (1997). Evaluation of percutateous gastrostomy as a technique for permanent gastropexy. Veterinary Surgery 26, 235-241.

Wilson E.R., Henderson R.A., Montgomery R.D., Kincaid S.A., Wright J.C., Hanson R.R. (1996). A comparision of laparoscopic and belt-loop gastropexy in dogs. Veterinary Surgery 25, 221-227.

Whitney W.O., Scavelli T.D., Matthiesen D.T., Burk R.L. (1989). Belt-loop gastropexy: technique and surgical re- 
sults in 20 dogs. Journal of the American Animal Hospital Association 25, 75-83.

Wingfield W.E., Cornelius L.M., Deyoung D.W. (1975). Pathophysiology of the gastric dilatation-torsion complex in the dog. Journal of Small Animal Practice 15, 735-739.

Woolfson J.M., Kostolich M. (1986). Circumcostal gastropexy: Clinical use of the technique in 34 dogs with gas- tric dilatation-volvulus. Journal of the American Animal Hospital Association 22, 825-830.

\section{Persbericht}

\section{MSD Animal Health lanceert Activyl ${ }^{\circledR}$, het eerste vlooienmiddel dat werkt met bioactivatie}

\section{Activyl $^{\circledR}$, een nieuwe innovatiestrategie die zich richt op veiligheid}

Met Activy $l^{\circledR}$ richt MSD Animal Health zich in haar onderzoek en ontwikkeling op veiligheid voor de mens, het dier en de omgeving. Zo werd indoxacarb, het actief bestanddeel van Activy $1^{\circledR}$ gekozen om wille van zijn krachtige en doelgerichte insecticide activiteit. Het actief bestanddeel is een pro-insecticide en wordt omgezet in een actieve metaboliet door de enzymen van de vlo. Het is de eerste molecule in de diergeneeskunde die werkt via bioactivatie. Door EPA (Environmental Protection Agency) in de Verenigde Staten werd het label « verminderd risico » toegekend aan het actieve bestanddeel, Indoxacarb.

\section{Bewezen efficiëntie tegen vlooieninfestaties bij de kat en de hond}

Activy $l^{\circledR}$ wordt gebruikt voor de behandeling en preventie van vlooien. Activy $l^{\circledR}$ kan gebruikt worden als onderdeel van een behandelingsstrategie tegen vlooienallergiedermatitis (VAD).

Uit praktijkonderzoek in Europa is gebleken dat Activyl ${ }^{\circledR}$ een werkzaamheid heeft van meer dan 95\% gedurende minstens vier weken.

Activyl ${ }^{\circledR}$ werkt ook op de ontwikkelingsstadia van vlooien die aanwezig zijn in de omgeving van het dier. 